\title{
A narrativa como opção metodológica de pesquisa e formação de professores
}

\author{
Maria Goreti da Silva Sousa* \\ Carmen Lúcia de Oliveira Cabral ${ }^{* *}$
}

\begin{abstract}
Resumo
O presente artigo é fruto das discussões gestadas na disciplina Pesquisa Narrativa em Educação do Doutorado em Educação do PPGED-UFPI, o principal objetivo é refletir sobre as contribuições da narrativa no contexto da pesquisa e da formação de professores. A narrativa de formação tem se constituído no cenário educacional como uma das opções metodológicas dentre os diversos métodos que já apresentam campo estabelecido. É, por sua natureza, carregada de significados e características próprias, permitindo-nos entender como seus componentes desencadeiam e proporcionam aos sujeitos a problematização, a revelação, a compreensão e o processo de reflexão sobre a prática docente através de diferentes técnicas e instrumentos. A construção de narrativas, sua leitura, análise, discussão, em contextos de formação inicial e contínua, consubstanciam-se em potencialidades no desenvolvimento pessoal e profissional dos professores, contribuindo para o processo de profissionalização docente.

Palavras-chave: Narrativa de formação; Formação de professores; Profissão docente.
\end{abstract}

\section{A narrative as option and research methodology teacher education}

\begin{abstract}
This article is the result of discussions conducted in the class of Narrative Research in the Doctorate in Education PPGED - UFPI Education, the main objective is to reflect on the potential of narrative in the context of research and teacher education. The narrative of training has been constituted in the educational scene as one of the methodological choices among the various methods that have already established field. It is, by its nature, full of meanings and characteristics, allowing us to understand how its components trigger and provide the subjects the questioning, revelation, understanding and reflection on the teaching practice through different techniques and tools. The construction of narratives, its reading, analysis, discussion, in the contexts of initial and continuing training, embodies the potential in personal and professional development of teachers, contributing to the teaching professionalization.
\end{abstract}

Keywords: Narrative training; Teacher education; Teaching profession.

\section{Introdução}

Este estudo resulta dos debates desenvolvidos na disciplina Pesquisa Narrativa em Educação do Doutorado em Educação do PPGEd UFPI, cujo objetivo é refletir sobre ascontribuições da narrativa no contexto da pesquisa e da formação de professores. No decorrer das últimas décadas, passou-se a reconhecer nocampo educacional, de forma crescente, a importância da narrativa como metodologia de investigação e de desenvolvimento pessoal e profissional de professores.

Podemos dizer que a narrativa comporta dois aspectos essenciais: uma sequência de acontecimentos e uma valorização implícita dos acontecimentos relatados (PRADO; SOLIGO, 2003). No tocante às alternativas presentes na literatura, o uso das narrativas tem se apresentado como uma estratégia para os cursos de formação de professores e para o desenvolvimento profissional. Alguns gêneros são mais comuns, quando presentes na maneira como essa narrativa se expressa, dentre os quais podemos destacar os diários de aula, as notas de campo, os memoriais, as cartas pedagógicas, os ateliês biográficos, as entrevistas narrativas e outros.

Para o desenvolvimento desta investigação, buscamos fundamentação em diversos autores que discutem a narrativa no contexto da pesquisa educacional. Destacam-se, dentre outros: Bolivar (2002), Nóvoa (1992), Passeggi (2012), Benjamin (1993), Sousa (2012), Zabalza (2004).

Este artigo está estruturado em quatros partes: a primeira foca a introdução, contextualizando o estudo; a segunda parte se refere à discussão sobre a narrativa como opção

*Instituição de Ensino UFPI/Teresina. Endereço eletrônico: mgsmoises@ hotmail.com

**Instituição de Ensino UFPI/Teresina. Endereço eletrônico: elisabethlattes@gmail.com 
metodológica no contexto da formação de professores; a terceira apresenta recorte de algumas técnicas e instrumentos mobilizadores das narrativas; e a quarta trata das considerações finais acerca do estudo.

\section{Caracterizando a narrativa no âmbito de uma metodologia de pesquisa e de formação de professores}

A narrativa faz parte da história da humanidade e, portanto, deve ser estudada dentro dos seus contextos sociais, econômicos, políticos, históricos, educativos. É comum ouvir através de narrativas diversas que os seres humanos são, por natureza, contadores, narradores de história, e que gerações e gerações repetem esse ato quase que involuntariamente uns aos outros. Narradores de Javé é um bom exemplo que se aplica a esse contexto de discussão, tratando-se, portanto, de um filme brasileiro de 2003, do gênero drama, dirigido por Eliane Caffé, que narra a verdadeira história dos habitantes de um pequeno vilarejo do Vale de Javé e o medo destes moradores em relação a uma represa que precisa ser construída, representando a inundação do vilarejo pelas águas. E a única chance que os moradores têm para não ficarem desabrigados é provando que esse lugar tem uma história, uma identidadeprópria a ser preservada.

Nesse enredo, retratara importância da rememoração como forma de reconstrução de histórias de vida, tanto numa perspectiva individual quanto social, é fundamental. Nesse sentido, há o reconhecimento de todos de que a tradição oral se fortalece quando vinculada à escrita, pois faz com que as palavras sejam viabilizadas através da ação.

Consubstancialmente, os acontecimentos narrados de uma história tomam da totalidade os seus significados. Esse todo narrado vai sendo tecido a partir das partes selecionadas, "[...] portanto, a narrativa não é apenas o produto de um 'ato de contar', ela tem também um poder de efetuação sobre o que narra" (DELORY, 2012, p. 82). Assim, a narrativa constitui-se no ato de contar e de revelar o modo pelo qual os sujeitos concebem e vivenciam o mundo.

Por conseguinte, o papel do intérprete é fundamental na narrativa, haja vista que ele tem como missão extrair o significado dos constituintes da narrativa no todo de um enredo, o qual, por sua vez, deve ser extraído da sucessão de eventos. Situação essa bem evidente no filme Narradores de Javé. Infere-se, daí, que uma história é composta por uma rede de intenções, de ações, de vivências, $\mathrm{e}$, nesse contexto, os personagens representam e experienciam situações em movimento nas quais se transformam. Nessa perspectiva, há ação e reação dos sujeitos envolvidos na tessitura da narrativa.

É esse caráter flexível da memória, tecida na relação com o outro, que permite aos sujeitos refazerem suas histórias, nas suas lembranças, resistindo àquilo que os incomoda, acrescentando fatos oriundos do seu desejo de que tivesse sido diferente, como novas possibilidades para suas vivências. Assim, entendemos que as situações narradas são revividas e reelaboradas no processo de rememoração. A discussão remete-nos [nos leva?], também, a estabelecer uma relação com a obra, Guilherme Augusto Araújo Fernandes, de autoria de Mem Fox. Na obra, um garoto busca, através de alguns dispositivos, resgatar a memória de uma senhora que vivia em um asilo e assim trazer à tona sua memória. É essencial também compreender essasequência espaço temporal presente na narrativa. Desse ponto de vista, o enredo é situado relacionado a determinado contexto espacial e temporal, gerenciado numa sinergia de eventos.

Ainda no tocante à memória, Galzerani (1999), seguindo Benjamin, afirma que é, sobretudo, experiência vivida. A rememoração permite que dimensões pessoais esquecidas possam ser recuperadas e situadas no tempo. A referida autora também compara a memória a um cenário no qual se entrecruzam as lembranças, o passado, o presente e também o futuro. Além da simples lembrança, a memória constitui uma viagem no tempo, e narrar é, dentre outras, rememorar experiências diversas quer da vida pública ou da vida privada. Tais percepções evidenciam que a unidade narrativa é constituída de vivências e experiências, adquiridas e construídas no decorrer da história de vida do ser humano que cristalizam e se constituem em imagens que são retomadas em situações cotidianas.

A referida unidade não se configura como 
homogênea, nem lógica, visto que há conflitos e tensões que deixam impressões na vida do indivíduo, ou seja, as vidas pessoais injetam situações que fazem parte de um conhecimento pessoal, fruto de episódios passados e de contextos específicos. Ao relacionar todos os componentes descritos com a formação de professores, tem-se elementos contundentes que configuram o professor como um narrador, um sujeito ativo da sua própria história de vida e de formação.

A opção pela narrativa, como uma das possibilidades para esta discussão, fundamenta-se também em Benjamin (1993, p. 201) quando afirma que o "[...] narrador retira da experiência o que ele conta $[\ldots .$.$] ", sendo, portanto, essas experiências,$ conforme o autor, as fontes originárias de todo narrador. Assim, as experiências vivenciadas pelos sujeitos desta investigação vão intercambiar-se com diferentes momentos da sua vida pessoal e de formação profissional. Faz-se referência também a Sousa (2012, p. 46), quando revela que “[...] narrar histórias e contar a vida caracteriza-se como uma das possibilidades de tecer identidade, de compreender como nos tornamos professores e das configurações que nos são forjadas nos nossos percursos de vida-formação".

Discutir narrativas no âmbito da formação é considerá-la também, dentre as diversas utilidades, uma investigação, ao se levar em conta que:

La investigación narrativa se utiliza cada vez más en estudios sobre ala experiencia educativa. Tiene una larga historia intelectual tanto dentro como fuera de La educación. La razón principal para El uso de La narrativa em La investigación educativa es que los seres humanos somos organismos contadores de historias, organismos que, individual y socialmente vivimos vidas relatadas (CONNELLY; CLANDININ, 1995, p. 11).

Essa metodologia de formação valoriza o desenvolvimento profissional dos professores como adultos, levando em conta o seu autoconhecimento, seus diferentes saberese suas experiências constituídas ao longo de uma vida. Esses estudos, reflexões e discussões incitamnova forma de pensar sobre a forma de aprender dos professores. Por conseguinte, considera-se que a abordagem (auto)biográfica ou biográfico-narrativaimprime a organização da trajetória pessoal e profissional, a reflexão sobre as práticas, a construção de novos conhecimentos.

A narrativa torna-se, portanto, relevante para o contexto de formação em que se concebeo professor como narrador-personagem-escritor de histórias que se constituem a partir de diversas situações de formação. As pesquisas revelam que os professores, quando os falam sobre os dilemas imbricados no seu fazer docente, transportam, ao mesmo tempo, dados de sua trajetória de vida. Isso aponta para diferentes modos de ver, conceber a prática profissional e promover avanços significativos na formação docente.

De acordo com Goodson (1992), ao ouvir a voz dos docentes, podemos reconhecer queos dados de suas vidas são relevantes, na medida em que os projetos pessoais estão articulados a outros de natureza coletiva; o contexto social, cultural, econômico e político influencia na constituição da pessoa e do profissional; a história de vida pessoal e profissional de cada um coaduna-se com sua prática; são importantes elementos no sentido de se pensar a maneira pela qual pode se realizar seu desenvolvimento profissional.

As discussões em torno das narrativas ancoram-se também nos postulados de Abrahão; Passeggi (2012, p. 61) quando defendem que:

O uso de narrativas [...] em contextos de formação inicial, e continuada, ancora-se no pressuposto dessa automização, no sentido em que o ato de explicitar para si mesmo e para o outro os processos de aprendizagem, adotando-se um posicionamento crítico, é suscetível de conduzir a pessoa que narra à compreensão da historicidade de suas aprendizagens e, portanto, de autorregular seus modos de aprender num direcionamento emancipador.

As narrativas, nesse aspecto, levam-nosà compreensão da historicidade do sujeito, do voltar para si num processo de reflexão. 
Face ao exposto, compreende-se que as narrativas são fundamentais para o desenvolvimento profissional e que as vidas dos professores estão entrelaçadas com a história da própria sociedade. Logo, a cultura da escola, enquanto instituição educadora e da profissão, possibilitacompreender a dimensão singular e complexa da prática docente, significando e ressignificando os processos de formação.

A seguir, elegeram-se alguns instrumentos mobilizadores das narrativas como processos de reflexão sobre a prática docente, na perspectiva do desenvolvimento pessoal e profissional.

\section{Recorte de algumas técnicas e instrumentos mobilizadores das narrativas}

As pesquisas narrativas são constituídas, geralmente, por relatos ou registros escritos que se apresentam através de diferentes técnicas e instrumentos. A seguir, um esboço de alguns deles:

\section{Os diários de aula}

Pensar a produção do diário de aula como instrumento metodológico da prática educativa para mobilizar as narrativas num processo de pesquisa e formação é fundamental nesta discussão.

Conforme postulam Porlán; Martín (1997, p. 18), o "[...] Diário de aula apresenta-se como instrumento que permite ao professor investigar e refletir sobre a prática educativa, testemunho biográfico da sua experiência". Segundo esses autores, a escrita do diário, com certa periodicidade, permite ao professor refletir sobre seu plano de aula e suas ações educativas. Corrobora Zabalza (2004, p.13): “os diários de aula [...] são documentos em que professores e professoras anotam suas impressões sobre o que vai acontecendo em suas aulas [...]”. Em razão desse entendimento, o diário se torna uma espécie de guia, em que sempre é possível voltar aos registros para rever o que foi realizado, possibilitando uma constante reflexão do fazer docente.

Os autores definem o significado dos diários de aula como instrumentos de formação. Zabalza (2004, p. 18) destaca ainda que os diários são instrumentos que se constituem em narrações feitas por professores. Enfatiza que o diário é um importante documento para o desenvolvimento pessoal pela sua riqueza de informações que seopõeà dimensão descritiva com a dimensão reflexivo-pessoal e "torna-se [...] um grande recurso para explicar os próprios dilemas em relação à atuação profissional".

No sentido de integrar o vivido através do narrado num processo de reflexão, pontua-se em que medida os diários impactam positivamente na prática docente. Para Zabalza (2004, p. 16-27), quatro âmbitos de impacto podem ser significativos nesse gênero textual:

1. O acesso ao mundo pessoal dos professores;

2. Os diários como um grande recurso para explicitar os próprios dilemas em relação a atuação profissional;

3. Os diários como recurso de acesso a avaliação e ao reajuste de processos didáticos;

4. Os diários como recurso para o desenvolvimento profissional permanente.

A meu ver, nos diários de aula, há uma integração da narrativa como umametodologia de formação que contribui para o desenvolvimento profissional de professores por meio da memória, da escrita, do afastamento da ação docente, da reflexão, não mais na ação, mas sobre as ações. Esse processo permite ao profissional um conhecimento de si, tendo em vista a perspectiva de questionamento mais sistemática, de compreensão de pontos que o incomodam e de aprofundamento do conhecimento, num movimento contínuo que permitirá a melhoria da sua atuação docente.

Nesse sentido, a narrativa promove a reflexão. A concepção de Zabalza (2004) reafirma a contribuição dos diários, a partir de um trabalho de formação e de investigação realizado com docentes. Esse autor fez uso dos diários de aula para identificar os dilemas presentes na prática desses profissionais erealizou estudo focando várias fases do trabalho desses protagonistas, apresentando também resultados sobre quais eram os dilemas que os docentes pesquisados enfrentavam. Os diários tornaram-se, portanto, importantes recursos para elucidar o contexto da prática docente e para 
compreender o pensamento dos docentes.

\section{O memorial}

O memorial é um texto em que o autor relata a própria história de vida, evidenciando fatos que considera mais relevantes no decorrer de sua existência. O Memorial de formação é umdos modos de expressão de narrativas autobiográficas que se generaliza no Brasil, a partir dos anos 1990, seja como trabalho de conclusão de curso (TCC), seja como prática reflexiva no contexto institucional de formação de professores (ABRAHÃO; PASSEGGI, 2012).

Um memorial de formação é acima de tudo uma forma de narrar nossa história por escrito para preservá-la do esquecimento. Configura-se o lócus da contação de uma história oculta aos olhos dos mais diversos leitores - a da experiência vivida por cada um de nós. Quando narramos nossa experiência de vida quer seja pessoal ou profissional, é possível produzirmos no nosso semelhante não só a percepção, mas sobretudo a compreensão daquilo que estamos fazendo e do que pensamos sobre o que fazemos. A produção é rica de acontecimentos referentes à experiência de formação, à prática profissional e também à vida.

As pesquisas revelam que o memorial se define, dentre outras possibilidades, pela formação; circunscreve, dentre outras possibilidades, a formação em um período da vida em que o discente imprime suas memórias, quer seja no transcurso de um curso uma disciplina, programa, trajetória profissional (registrar a prática docente num processo evolutivo) ou formação humana geral. Nesse sentido, a escrita de um memorial de formação é sempre a partir do campo da educação. A questão principal é articular formação e prática docente, haja vista ser o sujeito ator e personagem ao mesmo tempo.

A referência principalna escrita de um memorial é sempre o lugar profissional que se ocupa. Nesse percurso de resgate, às vezes faz-se necessário lançarmos mãos de memórias relacionadas a outras experiências vivenciadas com outros sujeitos, familiares ou não, desde que contribuam para esse processo formativo. É importante destacarmos passagens que retratem experiências positivas e/ou negativas, ou seja, todos os acontecimentos pertinentes ao memorial. Assim,

O êxito da escrita do memorial se realizaria quando o autor explora o potencial da refletividade autobiográfica e se deixa envolver pelo encantamento estético e ético do fazer da vida intelectual e profissional um texto acadêmico como arte autoformadora de si mesmo como profissional (PASSEGGI, 2011, p. 36).

As memórias inserem-se, assim, nas abordagens (auto)biográficas de formaçãoinvestigação; o foco que trazem à tona são as histórias de vida e/ou que focalizam diferentes aspectos da trajetória do narrado.

$\mathrm{Na}$ visão de Bolívar (2002), as histórias pessoais podem configurar-se como um meio para conhecer a prática, ao oportunizarem a compreensão; como um método para aprender a partir da prática, possibilitando a revisão e a crítica tanto da ação como da prática, pois, ao repensá-la, existe a oportunidade de criar, de mudar e de explorar os limites da experiência.

No trabalho com memórias, muita coisa entra em jogo. O sujeito aciona seus conhecimentos, crenças, valores, alegrias e tristezas, decepções e conquistas e expõe sua identidade, fruto de diferentes contextos, os quais se entrelaçam numa sucessão do tempo que ora aproxima-se e ora distancia-se do seu eu. Bolívar (2002), apoiando-se em Nóvoa (1992), intima-nos a vero "balanço de vida", como reflexão crítica, como algo indispensável para se compreender como o adulto vai constituindo a sua formação e como as diversas experiências de vida pessoal e profissional fundamentam-se em pilares para o processo formativo e autoformativo.

\section{Entrevista narrativa}

Dado o valor formativo que a entrevista carrega, é importante observar que tal técnica pode significar importante contribuição para a pesquisa. A relevância da entrevista como técnica utilizada nas pesquisas qualitativas é amplamente reconhecida, especialmente nas pesquisas educacionais.

A Entrevista Narrativa configura-se como uma técnica de coleta de dados utilizada na 
pesquisa; seu nome deriva da palavra latina narrare, relatar, contar uma história. Segundo Jovchelovitch; Gaskell (2010), a entrevista narrativa (EN), sistematizada por Schütze, estimula quem vai ser entrevistado a narrar episódios importantes da vida, configurando-se esse ato de contar/narrar e escutar histórias em um método para atingir seus objetivos. Nesse sentido, a narrativa é incitada por questões específicas, a partir do momento em que o narrador começa a contar sua história, conservando ele próprio a fluição da narrativa.

Desse modo, a entrevista narrativa permite ao narrador contar a história sobre algum acontecimento relevante de sua história de vida e do contexto do qual faz parte: "[...] sua idéia básica é reconstruir acontecimentos sociais a partir da perspectiva dos informantes, tão diretamente quanto possível" (JOVCHELOVITCH; BAUER, 2010, p. 93).
Essa técnica de pesquisa de cunho qualitativa, denominada não estruturada, contrapõese ao tradicional modelo pergunta-resposta da grande maioria das entrevistas que definem a estrutura das entrevistas, ordena as perguntas e as faz a partir de seu próprio vocabulário.

Jovchelovitch e Bauer (2010) defendem que existe uma estrutura na narrativa, que eles chamam de paradoxo da narração, a qual se consubstancia nas exigências das regras implícitas que permitem o contar histórias. Portanto, faz-se necessário estabelecer a EN como técnica de entrevistas, com regras claras, por exemplo: como ativar o esquema da história; como incitar as narrações dos entrevistados; e depois de iniciada a narrativa, conservar a narração, seguindo a mobilização do esquema autogerador. A seguir, um quadro com as fases principais da entrevista narrativa:

Quadro 1 - Fases principais da Entrevista Narrativa

\begin{tabular}{|l|l|}
\hline Fases & Regras \\
\hline Preparação & $\begin{array}{l}\text { Exploração do campo (leitura de documentos, notas relatos, etc.); } \\
\text { Formulação de questões exmanentes (aquelas que refletem intenções do pesquisador, } \\
\text { suas formulações e linguagens. As questões exmanentes distinguem-se das imanentes } \\
\text { (temas, tópicos e relatos de acontecimentos que surgem durante a narração [...]) }\end{array}$ \\
\hline 1 Iniciação & $\begin{array}{l}\text { Formulação do tópico inicial para a narração; } \\
\text { Emprego de auxílios visuais (dispositivos da memória fotografias, objetos, imagens e } \\
\text { outros). }\end{array}$ \\
\hline 2 Narração central & $\begin{array}{l}\text { Não interromper; } \\
\text { Somente encorajamento não verbal para continuar a narração; } \\
\text { Esperar para os sinais de finalização (coda). }\end{array}$ \\
\hline 3 Fase de perguntas & $\begin{array}{l}\text { Somente "Que aconteceu então?"; } \\
\text { Não dar opiniões ou fazer perguntas sobre atitudes; } \\
\text { Não discutir sobre contradições; } \\
\text { Não fazer perguntas do tipo “por quê?". }\end{array}$ \\
\hline 4 Fala conclusiva & $\begin{array}{l}\text { Parar de gravar; } \\
\text { São permitidas perguntas do tipo “por quê?"; } \\
\text { Fazer anotações imediatamente depois da entrevista. }\end{array}$ \\
\hline
\end{tabular}

Fonte: Fases principais da Entrevista Narrativa (JOVCHELOVITCH; BAUER, 2010, p. 97).

Compreendemos que do trabalho com a EN emergirão dimensões nem sempre previstas pelo pesquisador; no entanto, ao eleger a Entrevista Narrativa, é necessário que o entrevistador tenha o domínio da técnica e de suas particularidades. $\mathrm{Na}$ fase de preparação, é fundamental o conhecimento do campo da pesquisa empírica, seguida da elaboração das questões que lhe interessam enquanto pesquisador e que tenham relação com o objeto de estudo. $\mathrm{Na}$ fase de iniciação, o pesquisador apresenta uma questão gerativa narrativa que seja clara e específica, que estimule uma narração extemporânea, e não respostas pontuais, podendo fazer uso de alguns dispositivos de memória.

No percurso da narração central, 
recomenda-se não interromper o fluxo da narrativa e nem dificultá-la com perguntas, intervenções diretas ou avaliações. Na fase seguinte, seguem-se as investigações da narrativa, os fragmentos ainda não detalhados devem ser investigados, evitando opinar e fazer juízo de valor. A fala conclusiva consubstancia-se no final da gravação, e agora perguntas do tipo "por quê?" podem complementar algumas questões, seguidas de anotações imediatas após a finalização da entrevista.

Em relação à análise de entrevistas narrativas, Schütze $(1997,1083)$ citado por Jovchelovitch; Bauer (2010, p.106) propõe seis passos:

\section{Transcrição detalhada de alta qualidade} do material verbal.

2. Divisão do texto em material indexado (expressam referência concreta a 'quem fez $o$ quê, quando, onde e por quê') $e$ proposições não-indexadas (que vão além do conhecimento e expressam valores, juízos e toda forma de uma generalizada 'sabedoria de vida' dentre outros aspectos). 3. Uso de todos os componentes indexados para analisar o ordenamento dos acontecimentos para cada indivíduo, denominada de 'trajetórias'.

4. As dimensões não-indexados são investigativas como'análise do conhecimento' (opiniões, conceitos e teorias gerais, reflexões e divisões entre o comum $e$ o incomum, que permitem reconstruir teorias operativas sobre o objeto de estudo).

5. Agrupamento e comparação das 'trajetórias' individuais.

6. Trajetórias individuais colocadas dentro do contexto e semelhanças são estabelecidas permitindo a identificação de trajetórias coletivas.

Os procedimentos adotados por Schütze, a partir dos seis passos descritos, permitem ao pesquisador analisar as narrativas estabelecidas, seguindo fases distintas que permitirão a compreensão do fenômeno investigado.

\section{Cartas}

O gênero carta é instrumento de comunicação na sociedade há décadas e portador dos mais diversos conteúdos, sendo fundamental como instrumento de pesquisa e na formação de professores.

De acordo com Camini (2012), as cartas são escritas e se impuseram na história como documentos, evidências históricas. Segundo ela, ao se fazer uma retrospectiva na história da humanidade, é visível que escrever cartas é uma tradição secular e que foram escritas com diferentes propósitos, como o de informar grandes descobertas, declarar amor ou saudade, articular uma guerra, descrever lugares... Como exemplos, a Carta de Pero Vaz de Caminha, o Manifesto Comunista (1848), a Carta da Terra, a Carta do Chefe indígena (1854) e a Carta dos Sem Terra, dentre outras.

A carta é uma forma de comunicação. Estabelece uma ligação direta entre o leitor e o escritor e é um dos gêneros literários mais antigos. É uma forma de comunicação manuscrita ou impressa que pode ser destinada a uma ou mais pessoas.

De acordo com Lemos (2004), citado por Portal (2012), pelas cartas comenta-se, informa-se, elogia-se, "[...] ofende-se, apresenta-se, cobra-se, enfim, conjuga-se a infinidade de verbos que exprimem a riqueza contida no amplo contínuo que vai da trivialidade à nobreza da vida" (LEMOS apud PORTAL, 2012, p. 79).

A carta é também um instrumento pedagógico de uso fácil. A linguagem da carta é determinada pela intenção comunicativa e pela relação existente entre os pares. Dependendo da intenção, pode ser descritiva, persuasivoargumentativa e narrativa. Nesse particular, a carta se inscreve, neste trabalho, como narrativa e por contar alguma coisa relacionada à história de vida pessoal e profissional dos diferentes sujeitos.

Segundo Camini (2012, p. 29-30), um grande educador brasileiro que utilizou essa forma de comunicação foi Paulo Freire. Nos seus escritos, três importantes obras são reveladas,

[...] 'ensaios em forma de cartas'; a primeira, Cartas à Guiné-Bissau (1978); a segunda, Cartas a Cristina (1994) e, a terceira, Professora Sim, tia não: cartas a quem ousa ensinar (2002). Através destas, de forma coloquial, estabelece um profundo diálogo com o leitor/a e com sua própria prática.

De acordo com a autora, as cartas de Paulo Freire, compiladas nestes livros, ressignificam a 
importância da narrativa e da comunicação, sobretudo diante das demandas e convulsões sociais da era da tecnologia da comunicação, haja vista existir ainda um contingente de pessoas, especialmente no campo ezonas periféricas das pequenas e grandes metrópoles, sem acesso à internet e sem acondição de vir a acessar esse meio de comunicaçãoem curto prazo.

As duas primeiras obras, segundo Camini, foram narradas em dois contextos distintos e em diferentes condições, foram dirigidas intencionalmente a dois leitores: ao povo de GuinéBissau e a Cristina. Todavia, nenhuma dessas obras ficou aprisionada e represada a esses leitores, somente. Em seguida, se tornaram públicas e divulgadas a milhares de pessoas, quepuderam e podem acessá-las até hoje.

Camini (2012, p. 32), ao falar das Cartas Pedagógicas (CP) de Paulo Freire, postula que essas "[...] revelam a expressão da profunda humanidade de Freire" e que são expressivas narrativas por meio das quais ele dialoga com pais, educadores, discutindo os problemas contemporâneos, sugerem reflexões sobre o mundo, sobre a vida, sobre as pessoas, sobre a escola. Essa narrativa fala de cidadania, de posicionamento político, de indignação, de transformação, de esperança. Consubstancialmente, são cartas que proporcionam aprendizagens, reflexão, imergir no passado, liberar tensões a questionar o presente numa visão prospectiva.

As cartas têm sido utilizadas por professores como uma das estratégias pedagógicas. Portal (2012, p. 90) postula que "[...] as cartas podem ser um instrumento desvelador na construção do ser professor". Revela-nos que, ao dispor publicamente de seus relatos escritos de vivência e de experiências significativas, alunos, professores e educadores colaboram para reconstruir a memória pedagógica de suas trajetórias ou de certas práticas educativas em certo espaço, em um determinado momento histórico.

\section{À guisa de conclusões}

Ao refletir sobre as potencialidades da narrativa no contexto de pesquisa e formação de professores, compreendeu-se que essa metodologia constitui-se em espaço privilegiado de investigação, de aprendizagem profissional, experimentadas pelo professor em processo de formação, tanto inicial como continuada.

$\mathrm{O}$ aporte teórico, discutido neste artigo, implica entender que as narrativas são fundamentais para o desenvolvimento pessoal e profissional e proporcionam a reflexão sobre a ação docente, haja vista que esses sujeitos são considerados atores sociais que, ao narrarem suas histórias de vida, constroem nessa atividade, sua vida e sua profissionalização.

Destaca-se ainda que os diferentes instrumentos e técnicas apresentados, dentre outros de que a narrativa dispõe para que se tornem o seu canal de revelação, podem constituir fontes consubstanciais de inspiração e de conhecimento, proporcionando aos leitores um processo de reflexão profundo sobre as vidas dos outros e a sua própria vida.

Acreditamos que a narrativa, como opção metodológica de pesquisa e de formação de professores, insere-se na vertente investigaçãoformação, ao proporcionar aprendizagens, reflexão, revisitação ao passado, questionamentos sobre o presente numa visão prospectiva, permitindo a esses profissionais do ensino a revisão de posturas e crenças que foram se estabelecendo no decorrer da formação e da prática docente.

\section{Referências}

ABRAHÃO, M. H. M. B; PASSEGGI. Maria. As narrativas de formação, a teoria do professor reflexivo e a autorregulação da aprendizagem: uma possível aproximação. In: SIMÃ̃, V.; FRISON; ABRAHÃO. Autorregulação da aprendizagem $e$ narrativas autobiográficas. Natal: EDUFRN: Porto Alegre: EDIPUCRS, 2012.p. 53-71.

BAUER, M; GASKELL, G. Pesquisa qualitativa com texto, imagem e som: um manual prático. Petrópolis, RJ: Vozes, 2010.

BENJAMIN, Walter. O narrador: considerações sobre a obra de Nikolai Leskov. In:

Obras escolhidas. Magia e técnica, arte e política. v.1, São Paulo: Brasiliense, 1993.p.197-221.

BERTAUX, D. Narrativa de vida: a pesquisa e seus métodos. Natal, RN: Ed. UFRN, São Paulo: Paulus, 2008.

BOLÍVAR, A. Profissão professor: o itinerário 
profissional e a construção da escola. Bauru: EDUSC, 2002.

BRUNER, J. Atos de significação. Porto Alegre: Artes Médicas, 1997.

BUENO, B. O. O método biográfico e os estudos com histórias de vida de professores: a questão da subjetividade. Revista Educação e Pesquisa, São Paulo, v. 28, n. 1, p. 11-30, jan./jun. 2002.

CAMINI, I. Cartas pedagógicas: aprendizados que se entrecruzam e se comunicam. Porto Alegre: ESTEF, 2012. p. 56.

CONNELLY, F. M.; CLANDININ, D. J. In: LARROSA, J. (Org.). Déjame que te cuente: ensayos sobre narrativa y educación. Barcelona, E: Laertes, 1995.p.11-51.

DELORY, M. C. A pesquisa biográfica: projeto epistemológico e perspectivas metodológicas. In: ABRAHÃO, M. H. M. B; PASSEGGI. M. (Org.). Dimensões epistemológicas e metodológicas da pesquisa (auto) biográfica: Tomo I. Natal: EDUFRN: Porto Alegre: EDIPUCRS, Salvador, EDUNEB, 2012. p. 71-93.

NARRADORES de Javé, Ano de Lançamento (Brasil): 2003. Estúdio: Bananeira Filmes/ Gullane Filmes/Later it Productions, Distribuição: Rio filme, Direção: Eliane Caffé, Roteiro: Luiz Alberto de Abreu e Eliane Caffé, Produção: Vânia Catani, Música: DJ Dolores e Orquestra Santa Massa, Fotografia: Hugo Kovensky, Direção de Arte: Carla Caffé, Edição: Daniel Rezende.

FOX, Men. Guilherme Augusto Araújo Fernandes. São Paulo: Brinque-Book,1984.

GALZERANI, M. C. B. Percepções culturais do mundo da escola: em busca da rememoração. In: ENCONTRO NACIONAL DE PESQUISADORES DO ENSINO DE HISTÓRIA, 3., Campinas, 1999. Anais... Campinas: Gráfica da Faculdade de Educação da UNICAMP, 1999. p. 99-108.

GOODSON, I, F. Dar voz ao professor: as histórias de vida dos professores e o seu desenvolvimento profissional. In: NÓVOA, A. (Org.). Vidas de professores. Porto: Porto Editora, 1992. p. 63-78.

GUEDES, P. A. L.; SILVA, C. B. da; GOMES, G. G. Memórias de leitura e formação de professores. Campinas/SP: Mercado de Letras, 2008.

JOVCHELOVITCH, S; BAUER, M. W. Entrevista Narrativa. In: BAUER, M. W.; GASKELL, G. (Org.). Pesquisa qualitativa com texto, imagem $e$ som: um manual prático. Petrópolis, RJ: Vozes, 2010.p. 90-113.

NÓVOA, A. Os professores e as histórias de vida. In: NÓVOA, A. (Org.). Vidas deprofessores. Porto: Porto Editora, 1992. p. 11-30.

PASSEGGI, M.C. Injução Institucional e sedução autobiográfica: as faces autopoéticas e avaliativa dos memoriais, In: BARBOSA, T. M. N.; PASSEGGI, M.C. (Org.). Memorial acadêmico: gênero, injunção institucional, sedução autobiográfica. Natal: EDUFRN, 2011.p.21-35.

PORTAL, L. L. F. Cartas: um universo desvelador de significados na formação do formador?In: Práticas docentes e práticas de (auto) formação. ABRAHÃO, M. H. M. B.; FRISON, L. M. B.(Org.). Natal: EDUFRN: Porto Alegre: EDIPUCRS, 2012.p.79-105.

PORLÁN, R.; MARTÍN, J. El diário del professorun recurso para La investigación en el aula. Sevilla: Díada, 1997.

PRADO, G. V. T; SOLIGO, R. Memorial de Formação: quando as memórias narram a história da formação... Disponível em: <http://www.fe. unicamp.br/ensino/graduacao/downloads/proesfmemorial_GuilhermePrado_Rosaura Soligo.pdf > . Acesso em: 21 fev. 2013.

RAMOS, M. A.; GONÇALVES, R. E. As narrativas autobiográficas do professor como estratégia de desenvolvimento e a prática do professor. In: ALARCÃO, I. A formação reflexiva de professores: estratégias de supervisão. Porto, 
Portugal: Porto Editora, 1996. p. 123-149.

SOUSA, E, C; ALMEIDA, J, B. Narrar histórias e contar a vida: memórias cotidianas e histórias de vida de educadores baianos. In: ABRAHÃO, Maria Helena Menna Barreto. Pesquisa (auto) biográfica em rede. Natal: Ed. UFRN; Porto alegre: Ed. IPUCRS; Salvador; Ed. UNEB, 2012.p.29-31.

ZABALZA, M. Diários de aula: um instrumento de pesquisa e desenvolvimento profissional. Porto Alegre: ARTMED, 2004.

\section{Sobre as autoras}

Maria Goreti da Silva Sousa é Doutoranda em Educação, Mestre em Educação, Especialista em Psicopedagogia vinculada ao Programa de Pós- Graduação em Educação- PPGED-UFPI

Carmen Lúcia de Oliveira Cabral é Professora do Curso de Pedagogia e do Programa de Pós-Graduação em Educação da Universidade Federal do Piauí. Membro do Núcleo de Pesquisa sobre Formação e Desenvolvimento Profissional em Pedagogia - NUPPED.

Recebido em dezembro de 2014.

Aprovado em maio de 2015. 